\title{
Investigating the gender wage gap in Vietnam by quantile regression: Sticky floor or glass ceiling
}

\author{
TRAN THI TUAN ANH ${ }^{\mathrm{a}}$ \\ a University of Economics HCMC
}

\begin{abstract}
ART I C L E I NFO A B T RACT
Received 19 July 2017

Revised 15 Nov. 2017

Accepted 1 Jan. 2018

Available online

12 January 2018

JEL classifications:

E24; J16; O18

KEYWORDS

Inequality between men and women in the labor market is one of the issues that is of great interest in labor economics. The sticky floor effect occurs when the gender wage gap widens at the lower tail of the wage distribution. The glass ceiling effect in wage exists if the gender wage gap at the top of the wage distribution is wider than other positions. This study uses the dataset of VHLSS2014 and adopts quantile regression to investigate the existence of glass ceiling and sticky floor in the Vietnam's labor market. The overall results obtained of the entire sample show that there is sticky floor effect but no glass ceiling in the Vietnam's labor market. However, the results are different when it comes to each labor group. In terms of urban and rural areas, the sticky floor exists, but the glass ceiling does not in both areas. In terms of state and private sectors, while the glass ceiling exists in state sector, the stick floor is only present in the private sector.
\end{abstract}

Gender wage gap

Glass ceiling

Sticky floor

Quantile regression

Mincer-type wage

equation

Gender discrimination 


\section{Introduction}

Inequality between men and women in the labor market is one of the issues that are of great interest in labor economics. Many empirical studies have shown that wages of males are higher than for female workers. This happens in most countries around the world. Most of these studies focus on the average gender wage gap. However, in modern labor economics, an interesting phenomenon also attracts the attention of researchers: the gender wage gap at the upper and lower tails of wage distribution are usually higher than that the middle one. If the gender wage gap at lower tail quantiles is wider than that at the middle quantiles, it will result in a sticky floor effect. If the gender wage gap at upper quantiles is higher than the middle units, the glass ceiling is perceived to come in existence.

Glass ceiling can be interpreted as the phenomenon whereby women do quite well in the labor market up to a point after which there is an effective limit on their prospects. Glass ceiling implies that there seems to be an invisible barrier to female workers in occupation, in promotion or in wage that prevents females to reach the top compared to male workers who have the same productivity characteristics. The glass ceiling effect in wage exists if the gender wage gap at the top of the wage distribution is wider than other position, suggesting that females in wage ceiling have lower pay than their male counterparts.

The sticky floor effect occurs when the gender wage gap widens at the lower tail of the wage distribution. This refers to the case where women at the bottom of the wage distribution are more discriminated against than men and they may face greater disadvantages than at other quantiles.

Nowadays, sustainable development is a global concern. Gender equality is one of the important criteria for assessing the sustainable development of a country. Vietnam is also oriented toward sustainable development. Therefore, the improvement of gender wage gap is also one of the urgent requirements in global integration context. Investigating the existence of the glass ceiling sticky floor effect will determine the segments where the gender wage inequality actually occurs, and thereby help the government to build strategies for improving the gender inequality efficiently and effectively.

In addition, many studies reveal that inequality hurts economic growth. The 17th sustainable development goals of United Nation are to "achieve gender equality and empower all women and girls". The fact that female workers are stuck in low-income or bound by invisible barriers in high-income workers may limit their ability to contribute. Overcoming the effect of sticky floor and glass ceiling will create conditions for both men and women to contribute significantly to a country's development.

In Vietnam there are some empirical studies that demonstrate statistical evidence of gender wage gap. Liu (2004) used data from VHLSS 1992-1998 to investigate gender wage inequality in Vietnam by multiple linear regression and the Oxaca-Blinder (1973) 
decomposition. Hung and Reilly (2007) employed quantile regression to analyze the gender wage differential with the data for the period from 1992 to 2002. Anh (2015) also adopted quantile regression, while Machado (2015) analyzed the gender wage gap. All the above studies show the existence of gender wage inequality in Vietnam with strong statistical evidence. However, none of these papers have really focused on analyzing glass ceiling and sticky floor effects.

In addition, it is important to know at which quantiles of wage distribution the wage inequality is stronger. If the existence of the glass ceiling and sticky floor effects is confirmed, this will provide important guidance for policy makers to focus specifically on specific income groups where the gender wage inequality is the most serious.

Many studies in the world have examined the existence of glass ceiling and stick coatings in wage functions in many countries. However, very few studies are conducted in Vietnam. So, this article aims to investigate the existence of glass ceiling and sticky floor on the Vietnam's labor market in Vietnam. Not only are they investigated in the overall Vietnamese labor market, floor stickiness and glass ceiling effects are also verified by groups formed by living areas (urban/rural), sectors (state/private), education, and occupation.

This research contributes to the existing literature in several ways. Firstly, this study reinforces the empirical evidence of the existence of gender wage inequality in Vietnam. Secondly, this paper sheds light on the gender wage inequality in Vietnam. By investigating the existence of glass ceiling and sticky floor of wages, we confirm that the gender wage inequality mainly occurs in the low wage group (sticky floor effect) and is less severe in high wage group (no glass ceiling effect). Thirdly, this study also clarifies the glass ceiling and sticky floor effect in several groups of labor, such as urban/rural, state/private, educational, occupational groups.

The remaining of this study is organized as follows. Section 2 deals with a theoretical background and literature review. Section 3 presents the research methodology used in this study to investigate the sticky floor and glass ceiling effect. Section 4 reports and discusses the findings of the research. Finally, Section 5 summarizes some key results besides suggesting some policy implications and limitations of the study.

\section{Literature review}

In the representative studies of Albrecht et al. (2003) and Arulampalam et al. (2007), the statistical evidence was accumulated of the glass ceiling and sticky floor, indicating the wider gender wage differentials at the lower and upper tails of the wage distribution. On average, the gender wage gap can possibly be estimated using ordinary least squares and other mean regressions. However, OLS cannot be employed to investigate the gap beyond of the mean of the dependent variable, so it does not help in examining the glass ceiling and the sticky floor. Many statistical tools have been introduced to perform regression in other 
quantiles of wage distribution. With the introduction of the quantile regression by Koenker and Bassett (1978), nevertheless, the investigation of gender wage differentials throughout the wage distribution becomes more convenient. Since then quantile regression has become an effective empirical tool for examining the existence of sticky floor and glass ceiling.

Adamchik et al. (2003) measured the relative economic welfare of women in Poland during the transition. The authors analyze the male-female wage differential over the period from 1993 to 1997 after providing an account of gender differences in several labor market outcomes. Their results show that most of the explained portions of the wage differentials may be contributed to industrial and occupational segregation. They also verify that a substantial part of the wage gap remains unexplained.

Albrecht et al. (2003) used the 1998 data to show that the wage gap between males and females in Sweden rises throughout the wage distribution and moves faster in the top quantiles. They explain this as a strong glass ceiling effect. Albrecht et al. (2003) also performed decomposition by quantile regression to investigate the cause of gender gap. After controlling age, education, sector, industry, and occupation, they conclude that the glass ceiling still persists to a considerable extent.

Booth et al. (2003), using data from the British Household Panel Survey, indicated that full-time female workers are more likely to get promotion than their male counterparts. Controlling worker characteristics, they suggested that females may receive lower wage increases consequent upon promotion, although the chances of females being promoted are as large as those of males, which means that females and males could be promoted at the same rate. A sticky floor model of wage and promotion was constructed in order to account for their findings. As per sticky floor model, females' promotion prospects are just as reasonable as those of males, but they are stuck at the bottom of the wage scale for the new grade.

Kee et al. (2005) analyzed Australian gender wage gaps in both public and private sectors across the wage distribution by using the HILDA survey and quantile regression techniques. Additionally, the authors employs quantile regression decomposition analysis to examine whether differences in gender characteristics or differing returns between genders are attributed to the gap. Kee et al. (2005) detected a strong glass ceiling effect in the private sector. Moreover, after controlling many relevant factors, the acceleration in the gender gap across the distribution does not vanish, which proposes that the wage gap mainly causes by returns to genders.

Using data from the European Community Household Panel, De la Rica (2008) analyzed the gender pay gap across the wage distribution in Spain by longitudinal panel data and quantile regression techniques. The results showed that there exists the glass ceiling for highly educated workers, because the gap rises as moving up throughout the distribution. However, the gap falls gradually for less-educated workers. The author suggests that this can be interpreted by statistical discrimination exerted by employers in countries where less- 
skilled women have low participation percentages.

Using 1987, 1996, and 2004 data, Chi and $\operatorname{Li}$ (2008) indicated that the gender earnings gap in urban China has gone up throughout the earning's distribution, and the gap was wider at the lower quantiles. This can be seen as strong evidence of sticky floor effect. They also decomposed gender wage differentials, arguing that the gender endowment differences contribute less to the overall gender earnings gap than do return to worker characteristics. They also demonstrated that sticky floor can be associated with female production workers in low-paid career group working in non-state firms.

Agrawal (2013) examined the gender pay gap in the rural and urban areas in India. The findings showed evidence of the sticky floor effect in the urban sector and evidence of the glass ceiling effect in the rural sector. The gender wage gap is decomposed to clarify the contributions of coefficients and characteristics. The results illustrate the presence of discrimination against women. Additionally, women at the bottom of the wage distribution encounter more discrimination than those at the top.

Christofides et al. (2013) considered the gender wage differentials in 26 European countries with data in 2007 from Income and Living Conditions of the European Union Statistics. The magnitude of the gender wage differentials differ considerably among countries. The gap cannot be explained fully by the laborer's characteristics. Using quantile regressions, the authors revealed that the glass ceilings and sticky floors effects exist in several countries. They also found larger glass ceilings for full-time full-year employees. They suggest that country institutions and policies are relevant to unexplained gender wage gaps in systematic ways.

Finseraas et al. (2016) studied discrimination among recruits in the Norwegian Armed Forces during bootcamp. They revealed that females are perceived as less suited to be squad leaders than their male counterparts who have the same labor characteristics.

In Vietnam Pham and Reilly (2006) demonstrated the gender gap in Vietnam using VHLSS1998 and 2002. Anh (2015) compared the VHLSS data for 2002 and 2012 using the quantitative regression and the decomposition method. Machado-Mata (2005) showed evidence that the gender wage differential occurs on all quantiles and the wage gap is entirely attributed to the difference in returns to labor characteristics received by men and women. However, Anh did not examine the existence of glass ceiling and sticky floor on the labor market in Vietnam.

According to the literature mentioned above, this study aims to employ quantile regression to examine the existence of the sticky floor and glass ceiling effect in Vietnam across the labor market. 


\section{Data and methodology}

\subsection{Data}

This study uses the dataset of VHLSS2014 to accomplish the research objectives. The VHLSS dataset collects information on a sample of households and communes that serves to assess the living standards across the country and regions. This includes the objective of assessing poverty and the economic inequality. The VHLSS survey consists of households, household members, and communes in all provinces/cities. The VHLSS sampling method is implemented through the consultancy and supervision of the National Institute of Statistical Sciences, UNDP, and the World Bank to ensure representative representation of the sample selected for the overall study. Because of the representative sample of the VHLSS, the VHLSS data is suitable for constructing the wage equation to investigate the existence of glass ceiling and sticky floor in Vietnam.

The total number of households surveyed in VHLSS 2014 is 46,995 households in 3,133 communes across 63 provinces. Information on employment and wages is provided in Section $4 \mathrm{~A}$ of the questionnaire. The sample comprises all the respondents in Section $4 \mathrm{~A}$ but excludes members out of working age. The sample also excludes members who are selfemployed workers.

\subsection{Methodology}

Using the VHLSS 2014 and referring to study of Albrecht et al. (2003), this study employs an extension of Mincer wage equation with the independent variables as listed in Table 1. The dependent variable is logarithm of hourly wage. Taking hourly pay will rule out the difference in wage due to being full-time or part-time workers as well as all factors that affect the working time of workers such as housework, child care, etc. Because the research objectives are to investigate the existence of glass ceiling and stocky floor and determine how wide the gaps are, the variable male is the key explanatory variable. This is a dummy variable, taking value 1 if the worker is male and zero if the worker is female. The regression coefficient of this dummy variable will help to measure the gender wage gap.

In addition to gender dummy variable, the wage regression also includes other independent variables as control variables. All the variables included in the model are listed in Table 1. 


\section{Table 1}

List of variables

\begin{tabular}{|c|c|c|}
\hline ID & Variables & Notes \\
\hline 1 & lnwage & Logarithm of hourly wage \\
\hline 2 & male & $=1$ for male workers; $=0$ for female workers \\
\hline 3 & age & Age of worker \\
\hline 4 & age2 & Age squared \\
\hline 6 & married & $=1$ if worker current marital status is married; $=0$ otherwise \\
\hline 7 & race & $=1$ if worker race is Kinh or Hoa; $=0$ otherwise \\
\hline 8 & Primary & $=1$ if worker's highest level of education is primary; $=0$ otherwise \\
\hline 9 & Secondary & $=1$ if worker's highest level of education is secondary; $=0$ otherwise \\
\hline 10 & Highschool & $=1$ if worker's highest level of education is highschool; $=0$ otherwise \\
\hline 11 & Vocational & $\begin{array}{l}=1 \text { if worker's highest level of education is vocational degree; = } 0 \\
\text { otherwise }\end{array}$ \\
\hline 12 & Bachelor & $=1$ if worker's highest level of education is bachelor; $=0$ otherwise \\
\hline 13 & Postgraduate & $=1$ if worker's highest level of education is postgraduate; $=0$ otherwise \\
\hline 14 & Manager & $=1$ if worker occupation is leader $/$ manager; $=0$ otherwise \\
\hline 15 & High level expert & $=1$ if worker occupation is high level expert; $=0$ otherwise \\
\hline 16 & Average level expert & $=1$ if worker occupation is average level expert; $=0$ otherwise \\
\hline 17 & Office staff & $=1$ if worker occupation is office staff; $=0$ otherwise \\
\hline 18 & Service & $=1$ if worker occupation is service; $=0$ otherwise \\
\hline 19 & Manual laborer & $=1$ if worker occupation is manual laborer $;=0$ otherwise \\
\hline 20 & Operation worker & $=1$ if worker occupation is operation worker; $=0$ otherwise \\
\hline 21 & Private & $=1$ if worker works in private sector; $=0$ otherwise \\
\hline 22 & State & $=1$ if worker works in state sector; $=0$ otherwise \\
\hline
\end{tabular}

The wage equation of this study is constructed as an extension of Mincer wage equation which is referred to Albrecht et al (2003). Estimation method is the quantile regression. Although quantile regression can be estimated for every quantile $\tau \in(0,1)$, we only report the results for some regular quantiles such as $0.1-0.25-0.5-0.75-0.9$. These quantile are chosen because this is a combination of quartiles and deciles which are commonly used in statistics. 
The model is:

$$
\begin{aligned}
\text { lnwage } & =\beta_{1}+\beta_{2} \text { male }+\beta_{3} \text { age }+\beta_{4} \text { age }{ }^{2}+\beta_{5} \text { married }+\beta_{6} \text { state }+\beta_{7} \text { private } \\
& +\beta_{8} \text { race }+\beta_{9} \text { urban }+\sum_{j=1}^{6} \alpha_{j} \text { education }_{j}+\sum_{j=1}^{5} \gamma_{j} \text { occupation }_{j}+u .
\end{aligned}
$$

The explanation of variables is listed in Table 1.

The quantile regression will be performed at some typical quantiles: $0.1-0.25-0.5-0.75$ - 0.9. The coefficient of the gender dummy variable will show the gender wage differentials at each quantile. The sticky floor effect occurs when females at the lower tail of the wage distribution are at greater disadvantages and the gap is wider at this lower tail. Thus, according to Booth et al. (2003), in order to verify the existence of the sticky floor in Vietnam, the coefficient of the gender dummy variable at quantile 0.1 is compared with that of quantiles 0.25 and 0.5 . If the gender wage gap at quantile 0.1 is significantly greater than the gap at quantiles 0.25 and 0.5 , there is statistical evidence for the existence of sticky floor in Vietnam.

Similarly, the glass ceiling effect occurs when the gender wage differentials are wider at the upper tail of the wage distribution. Therefore, according to Arulampalam et al. (2007), in order to verify the existence of the glass ceiling, the coefficient of the gender dummy variable at quantile 0.9 is compared with that of quantiles 0.5 and 0.75 . If the gender wage gap at 0.9 is significant greater than the gap at 0.5 and 0.75 , there is statistical evidence of the existence of glass ceiling in Vietnam.

In order to figure out the overall picture of the sticky floor and glass ceiling in Vietnam's labor market, this study will perform analyses of the entire population and some subpopulations: urban and rural areas, state sector and private sector, groups divided by education, and groups divided by occupations.

\section{Results and discussion}

\subsection{Descriptive statistics}

Table 2 shows the percentages of male and female workers in the sample as well as in each subgroup. The total number of observations for the entire sample is 5,512, of which the number of female workers is 2,407 (about $43.67 \%$ ) and the number of male workers is 3,105 (about $56.33 \%$ ). In the sample employed in the private sector are 1,454 (26.38\%) workers, among whom $618(42.5 \%)$ are female, and 836 male (57.5\%). The number of people working in the public sector is $785(14.24 \%)$, with the proportion of men in this group being $51.3 \%$ and $48.7 \%$ for women. For each group formed by education, the number of workers with bachelor degree is 1,774 (about 24.93\%) which is the highest proportion, of which $53.9 \%$ are female and $46.1 \%$ are male. The proportion of workers with postgraduate qualifications is 
relatively small at about $1.40 \%(=77 / 5512)$; particularly, the proportion of men with postgraduate qualifications is much higher than that of women (65.5\% versus $34.5 \%)$. At the remaining levels of education such as primary, lower secondary, highschool, and vocational levels, the proportion of male workers is always higher than that of female workers.

\section{Table 2}

Percentage of male and female laborers in the entire sample and in each subsample

\begin{tabular}{|c|c|c|c|c|c|}
\hline \multirow{3}{*}{ Sample } & \multicolumn{2}{|c|}{ Female } & \multicolumn{2}{|c|}{ Male } & \multirow{2}{*}{ Total } \\
\hline & Count & Percent & Count & Percent & \\
\hline & (1) & (2) & (3) & (4) & $(1)+(3)$ \\
\hline Total & 2407 & $43.67 \%$ & 3105 & $56.33 \%$ & 5512 \\
\hline \multicolumn{6}{|l|}{ Sectors } \\
\hline private & 618 & $42.5 \%$ & 836 & $57.5 \%$ & 1454 \\
\hline staterun & 785 & $48.7 \%$ & 828 & $51.3 \%$ & 1613 \\
\hline \multicolumn{6}{|l|}{ Education } \\
\hline Primary & 366 & $39.0 \%$ & 573 & $61.0 \%$ & 939 \\
\hline Secondary & 411 & $41.8 \%$ & 572 & $58.2 \%$ & 983 \\
\hline Highschool & 320 & $46.6 \%$ & 366 & $53.4 \%$ & 686 \\
\hline Vocational & 315 & $34.5 \%$ & 597 & $65.5 \%$ & 912 \\
\hline Bachelor & 741 & $53.9 \%$ & 633 & $46.1 \%$ & 1374 \\
\hline Postgraduate & 27 & $35.1 \%$ & 50 & $64.9 \%$ & 77 \\
\hline \multicolumn{6}{|l|}{ Occupations } \\
\hline Manager & 34 & $25.2 \%$ & 101 & $74.8 \%$ & 135 \\
\hline HighLevelExpert & 471 & $54.5 \%$ & 394 & $45.5 \%$ & 865 \\
\hline AverageLevelExpert & 293 & $61.0 \%$ & 187 & $39.0 \%$ & 480 \\
\hline OfficeStaff & 163 & $58.0 \%$ & 118 & $42.0 \%$ & 281 \\
\hline Service & 236 & $43.9 \%$ & 302 & $56.1 \%$ & 538 \\
\hline SkilledLaborer & 22 & $24.2 \%$ & 69 & $75.8 \%$ & 91 \\
\hline ManualLaborer & 380 & $33.2 \%$ & 764 & $66.8 \%$ & 1144 \\
\hline OperatingWorker & 296 & $41.9 \%$ & 411 & $58.1 \%$ & 707 \\
\hline
\end{tabular}

Table 3 demonstrates the mean and median wages of the two groups of male and female over the entire sample as well as subsamples. The log wage's mean value of males is higher 
than that of females on the whole sample. This not only occurs in the entire sample but also in every subsample which are split by urban/rural areas, by state/private sectors, by education and occupations. All gender wage differentials are statistically significant, suggesting that the gender wage gap actually exists. Table 3 also shows the median wage differentials between men and women. Similar to the mean wage differentials, the median of male wages is always higher than that of females over the whole sample as well as in all subsamples considered. All the median wage gap between men and women is always statistically significant.

These early comparisons show that male wages tend to be higher than female wages in both cases of mean wage and the median wage. However, this comparison does not help to see whether there is a sticky floor and glass ceiling. In the next step, it is necessary to conduct quantile regression to investigate the existence of glass ceiling and sticky floor.

\section{Table 3}

Comparison of lnwage between male and female groups

\begin{tabular}{|c|c|c|c|c|c|c|c|c|}
\hline \multirow{3}{*}{ Sample } & \multicolumn{2}{|c|}{ Female } & \multicolumn{2}{|c|}{ Male } & \multicolumn{4}{|c|}{ Difference } \\
\hline & \multirow{2}{*}{$\begin{array}{c}\text { Mean } \\
(1)\end{array}$} & \multirow{2}{*}{$\begin{array}{c}\text { Median } \\
(2)\end{array}$} & \multirow{2}{*}{$\begin{array}{c}\text { Mean } \\
(3)\end{array}$} & \multirow{2}{*}{$\frac{\text { Median }}{(4)}$} & \multirow{2}{*}{$\begin{array}{c}\text { Mean } \\
(5)=(3)-(1)\end{array}$} & \multirow{2}{*}{$\frac{\text { t-stat }}{(6)}$} & \multirow{2}{*}{$\begin{array}{c}\text { Median } \\
(7)=(4)-(2)\end{array}$} & \multirow[t]{2}{*}{$\begin{array}{c}\text { Pearson } \\
\text { chi2 }\end{array}$} \\
\hline & & & & & & & & \\
\hline Entire sample & 2.88 & 2.95 & 3.03 & 3.06 & 0.15 & $7.77^{* * *}$ & 0.11 & $31.71^{* * *}$ \\
\hline \multicolumn{9}{|c|}{ Urban - rural areas } \\
\hline Urban & 2.70 & 2.81 & 2.87 & 2.93 & 0.17 & $5.97^{* * *}$ & 0.11 & $37.94^{* * *}$ \\
\hline Rural & 3.06 & 3.08 & 3.22 & 3.24 & 0.16 & $6.06^{* * *}$ & 0.16 & $19.81^{* * *}$ \\
\hline \multicolumn{9}{|c|}{ Public - private sectors } \\
\hline Private & 2.86 & 2.91 & 3.06 & 3.07 & 0.20 & $5.43^{* * *}$ & 0.16 & $30.20^{* * *}$ \\
\hline State & 3.26 & 3.31 & 3.43 & 3.48 & 0.18 & $5.61^{* * *}$ & 0.16 & $23.36^{* * *}$ \\
\hline \multicolumn{9}{|l|}{ Educations } \\
\hline Primary & 2.54 & 2.67 & 2.76 & 2.85 & 0.22 & $5.147^{* * *}$ & 0.18 & $15.12^{* * *}$ \\
\hline Secondary & 2.74 & 2.81 & 2.83 & 2.89 & 0.09 & $2.14^{\star *}$ & 0.08 & $4.31^{* *}$ \\
\hline Highschool & 2.75 & 2.86 & 2.93 & 3.00 & 0.19 & $3.32^{* * *}$ & 0.15 & $10.64^{* * *}$ \\
\hline Vocational & 3.00 & 3.05 & 3.18 & 3.22 & 0.18 & $4.31^{* * *}$ & 0.16 & $20.48^{* * *}$ \\
\hline Bachelor & 3.27 & 3.35 & 3.53 & 3.57 & 0.26 & $6.97^{* * *}$ & 0.22 & $38.97^{* * *}$ \\
\hline Postgraduate & 3.76 & 3.86 & 4.00 & 3.94 & 0.24 & $1.94^{*}$ & 0.08 & 2.52 \\
\hline Occupations & & & & & & & & \\
\hline
\end{tabular}




\begin{tabular}{|c|c|c|c|c|c|c|c|c|}
\hline \multirow{3}{*}{ Sample } & \multicolumn{2}{|c|}{ Female } & \multicolumn{2}{|c|}{ Male } & \multicolumn{4}{|c|}{ Difference } \\
\hline & Mean & Median & Mean & Median & Mean & t-stat & Median & $\begin{array}{c}\text { Pearson } \\
\text { chi2 }\end{array}$ \\
\hline & (1) & $(2)$ & (3) & $(4)$ & $(5)=(3)-(1)$ & (6) & $(7)=(4)-(2)$ & \\
\hline Manager & 3.52 & 3.65 & 3.80 & 3.85 & 0.28 & $2.12^{* *}$ & 0.20 & $5.42^{* *}$ \\
\hline HighLevelExpert & 3.44 & 3.46 & 3.69 & 3.69 & 0.24 & $5.96^{* * *}$ & 0.23 & $28.69^{* * *}$ \\
\hline AverageLevelExpert & 3.16 & 3.26 & 3.33 & 3.35 & 0.17 & $2.87^{* * *}$ & 0.09 & $3.65^{*}$ \\
\hline OfficeStaff & 2.94 & 3.02 & 3.12 & 3.22 & 0.17 & $2.07^{* *}$ & 0.20 & $7.34^{* * *}$ \\
\hline Service & 2.59 & 2.68 & 2.73 & 2.81 & 0.14 & $2.20^{* *}$ & 0.12 & $6.82^{* * *}$ \\
\hline ManualLaborer & 2.59 & 2.73 & 2.96 & 3.01 & 0.37 & $9.76^{* * *}$ & 0.28 & $70.00^{* * *}$ \\
\hline OperationWorker & 2.89 & 3.00 & 3.13 & 3.14 & 0.24 & $5.71^{* * *}$ & 0.14 & $19.56^{* * *}$ \\
\hline LowSkilledLaborer & 2.48 & 2.53 & 2.63 & 2.72 & 0.14 & $3.71^{* * *}$ & 0.19 & $21.73^{* * *}$ \\
\hline
\end{tabular}

$*, * *, * * *$ : significant at $10 \%, 5 \%, 1 \%$ respectively

4.2. The gender wage differentials across the distribution

\section{Table 4}

Summary of stick floor and glass ceiling in Vietnam

\begin{tabular}{|c|c|c|c|c|c|c|c|c|}
\hline \multirow{2}{*}{ Sample } & \multicolumn{6}{|c|}{ The gender wage gap } & \multirow{2}{*}{$\begin{array}{l}\text { Sticky } \\
\text { floor }\end{array}$} & \multirow{2}{*}{ Glass ceiling } \\
\hline & OLS & 0.1 & 0.25 & 0.5 & 0.75 & 0.9 & & \\
\hline Entire & $0.223^{* * *}$ & $0.260^{* * *}$ & $0.203^{* * *}$ & $0.206^{* * *}$ & $0.205^{* * *}$ & $0.196^{* * *}$ & \multirow{2}{*}{ yes } & \multirow{2}{*}{ no } \\
\hline sample & [13.20] & [7.03] & {$[10.02]$} & {$[15.23]$} & {$[13.61]$} & [9.28] & & \\
\hline \multicolumn{9}{|c|}{ Urban - rural areas } \\
\hline \multirow[t]{2}{*}{ Urban } & $0.189^{* * *}$ & $0.218^{* * *}$ & $0.135^{* * *}$ & $0.206^{* * *}$ & $0.201^{* * *}$ & $0.191^{* * *}$ & \multirow{2}{*}{ yes } & \multirow{2}{*}{ no } \\
\hline & [8.35] & {$[5.47]$} & [5.79] & {$[10.44]$} & [9.62] & [5.37] & & \\
\hline \multirow[t]{2}{*}{ Rural } & $0.251^{* * *}$ & $0.280^{* * *}$ & $0.247^{* * *}$ & $0.217^{* * *}$ & $0.196^{* * *}$ & $0.226^{* * *}$ & \multirow{2}{*}{ yes } & \multirow{2}{*}{ no } \\
\hline & [9.89] & [4.59] & {$[7.71]$} & [9.73] & [8.18] & [7.07] & & \\
\hline \multicolumn{9}{|c|}{ State - private sectors } \\
\hline \multirow[t]{2}{*}{ State sector } & $0.149^{* * *}$ & $0.103^{* *}$ & $0.124^{* * *}$ & $0.125^{\star * *}$ & $0.159^{* * *}$ & $0.190^{* * *}$ & \multirow{2}{*}{ no } & \multirow{2}{*}{ yes } \\
\hline & [5.49] & [2.01] & {$[4.25]$} & [4.82] & [5.26] & {$[4.56]$} & & \\
\hline Private & $0.178^{* * *}$ & $0.261^{* * *}$ & $0.160^{* * *}$ & $0.166^{* * *}$ & $0.175^{\star * *}$ & $0.187^{* * *}$ & & \\
\hline sector & [5.52] & [3.29] & [4.58] & [6.16] & [6.28] & [4.04] & & \\
\hline
\end{tabular}


The regression equation (1) is performed on the entire sample as well as on each labor group to determine the glass ceiling and sticky floor effect. The coefficient of the gender dummy variable will indicate the gender wage gap. The estimated coefficients of this variable are presented in Table 4 and are represented by Figures 1-5 corresponding to each sample.

Table 4 presents the summary results of the existence of sticky floor and glass ceiling on the labor market in Vietnam. The overall results on entire sample show that there is sticky floor effect but no glass ceiling in Vietnam labor market. However, the results are different when analyzing in detail the entire sample and each labor group.

On entire sample

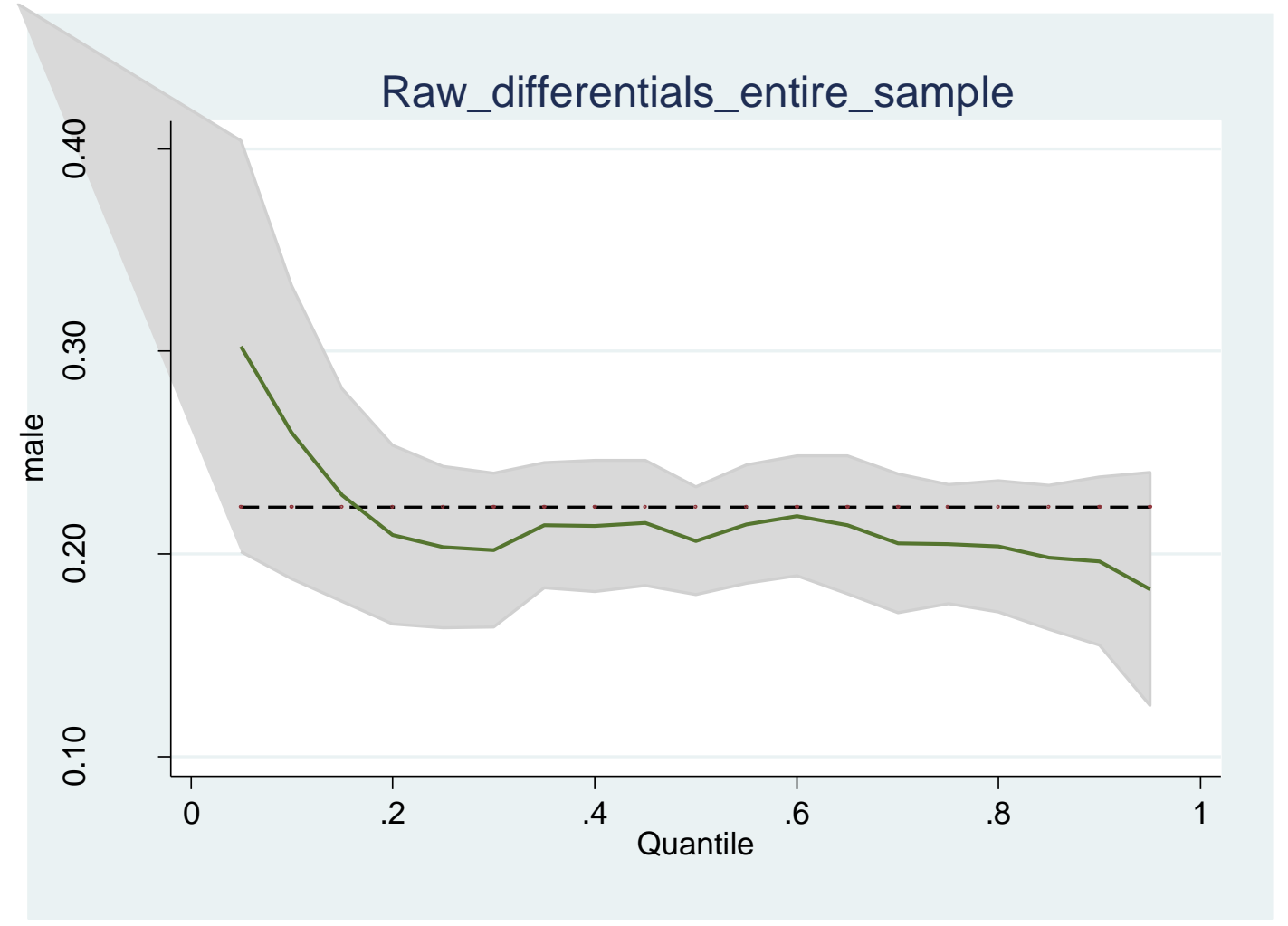

Figure 1. Gender wage gap in entire sample by OLS and quantile regression

Figure 1 demonstrates the gender wage gap in mean and in each quantile across the wage distribution on the entire sample which are reported in the first two rows of Table 4 . The horizontal dashed line represents the gender gap in mean wage and it is constant across all quantiles. The folded line represents the variation of gender wage gap across quantiles. As we can see from Table 4 and Figure 1, the gender wage gap tends to be higher at bottom of the wage distribution. The folded line in Figure 1 has the tendency to be higher at lower quantiles than that of middle quantiles, indicating that this statistical evidence supports the 
existence of a sticky floor in Vietnam labor market. However, the regression result on the whole sample did not provide statistical evidence for the existence of the glass ceiling because the gender variable's coefficient at quantile 0.9 is not greater than at 0.5 and 0.75 . Thus, with the results of wage regression for whole sample, this study reveals the statistical evidence for the existence of sticky floor but no evidence for the glass ceiling effect. To investigate more details about these effects in Vietnam, we continue to look at these effects in urban and rural areas.

In urban area

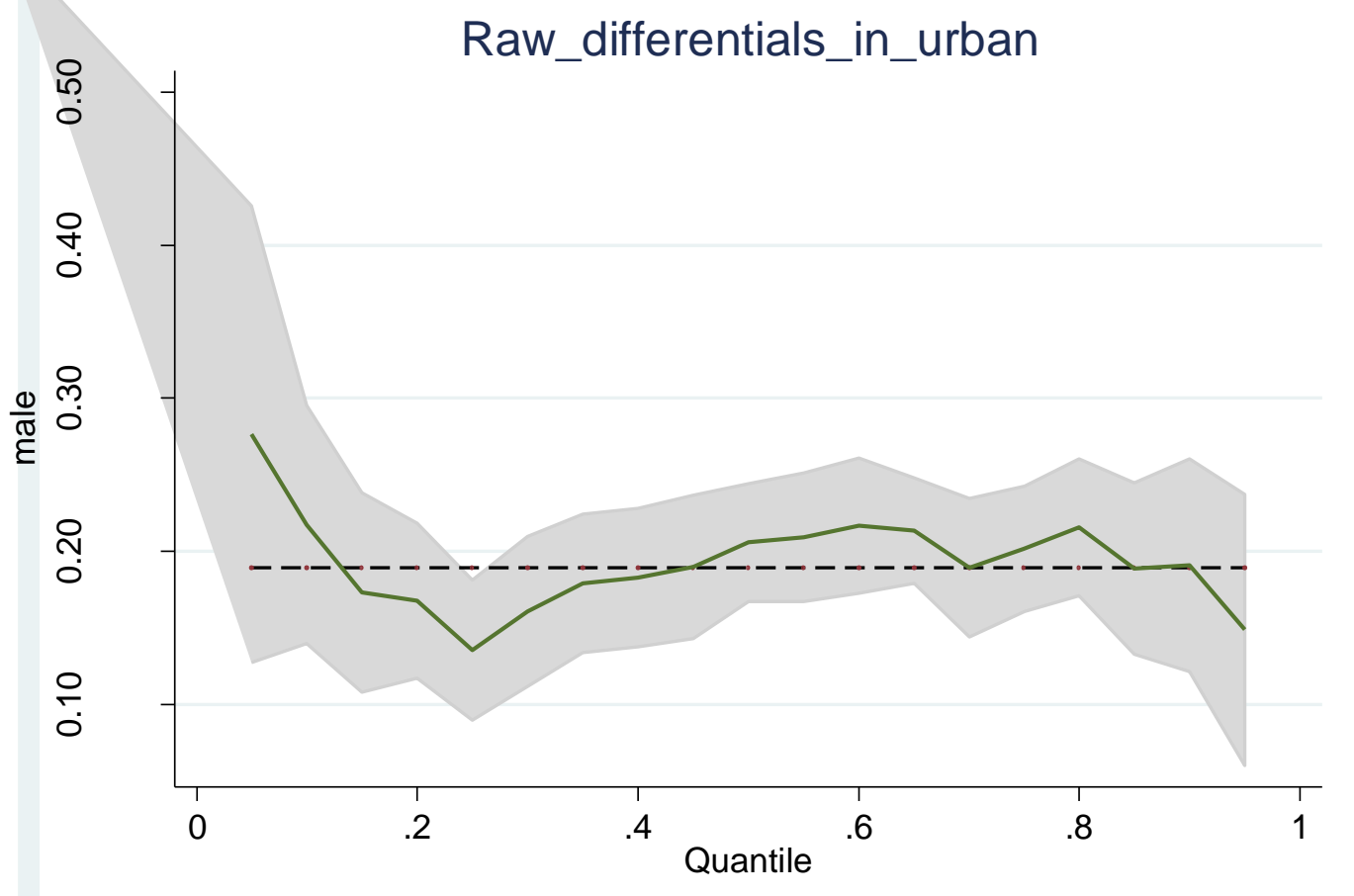

Figure 2. Gender wage gap in urban area by OLS and quantile regression

The results in Table 4 which are shown in Figure 2 show that the gender wage gap at the lower quantiles is higher than the wage gap in the middle quantiles. All the gaps are statistically significant. This is empirical evidence of the existence of a sticky effect on the wages of workers in urban areas. Meanwhile, the results do not provide any statistical evidence of the glass ceiling. The coefficient of the high quantiles (represented by 0.9) is lower than in the middle quantiles (represented by 0.5 and 0.75 ). The existence of sticky floor without glass ceiling is similar to the result obtained from the entire sample. 


\section{In rural area}

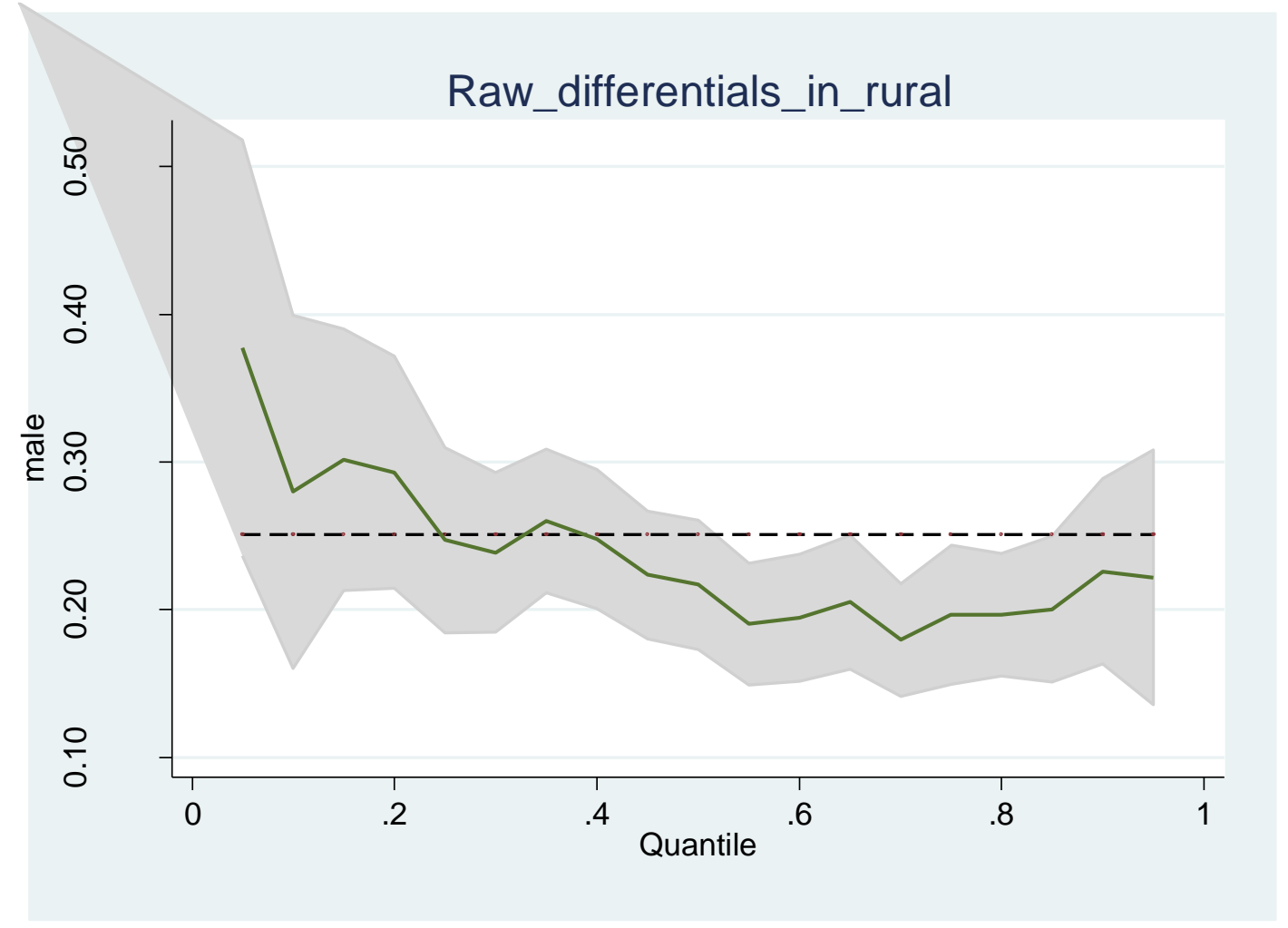

Figure 3. Gender wage gap in rural by OLS and quantile regression

Figure 3 shows the gender wage gap in rural areas. The coefficients at the bottom of wage distribution (represented by the quantile 0.1 in Table 4 ) are significantly higher than the gap at the middle quantiles. This is statistical evidence of the existence of a sticky floor in the rural wage equation. Similar to the result of urban area, the result in rural areas also shows no evidence for the existence of the glass ceiling effect. The gender pay gap at quantile 0.9 is not significantly higher than the gap at 0.5 and 0.75 quantiles. This can also be observed at the unclear upward trend of the curve line on the Figure 3.

In state sector

In addition to analyzing the gender wage gap in urban/rural areas, this research also examines the sticky floor and glass ceiling for state and private sectors. Figures 5 and 6 show the regression results in the state and private sectors, respectively. 


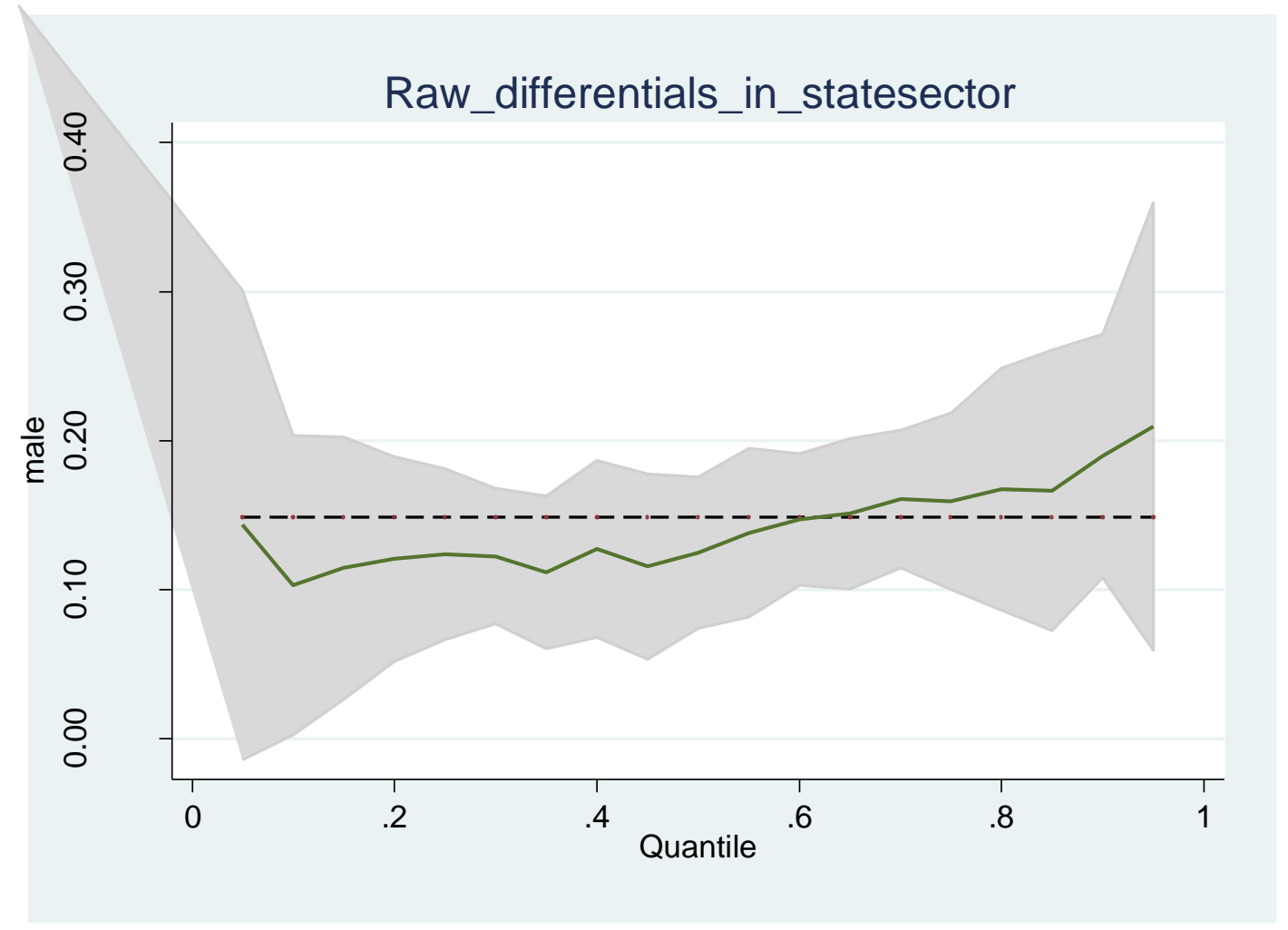

Figure 4. Gender wage gap in state sector by OLS and quantile regression

The increasing tendency of the wage gap widening along with the increase in the percentile can be seen in Figure 9. As the gender wage gap at top quantiles of the wage distribution is wider than at the middle, this is the statistical evidence of the existence of the glass ceiling in the state sector. And the results also show that there is no sticky floor in this sector.

\section{In private sector}

Considering the glass ceiling effect, although the regression coefficient shown in Table 4 of the 0.9 quantile is quite higher than that of the other quantiles, the difference is not statistically significant. The increasing trend across the top quantiles is unclear, which can be considered as having no glass ceiling effect in the private sector. 


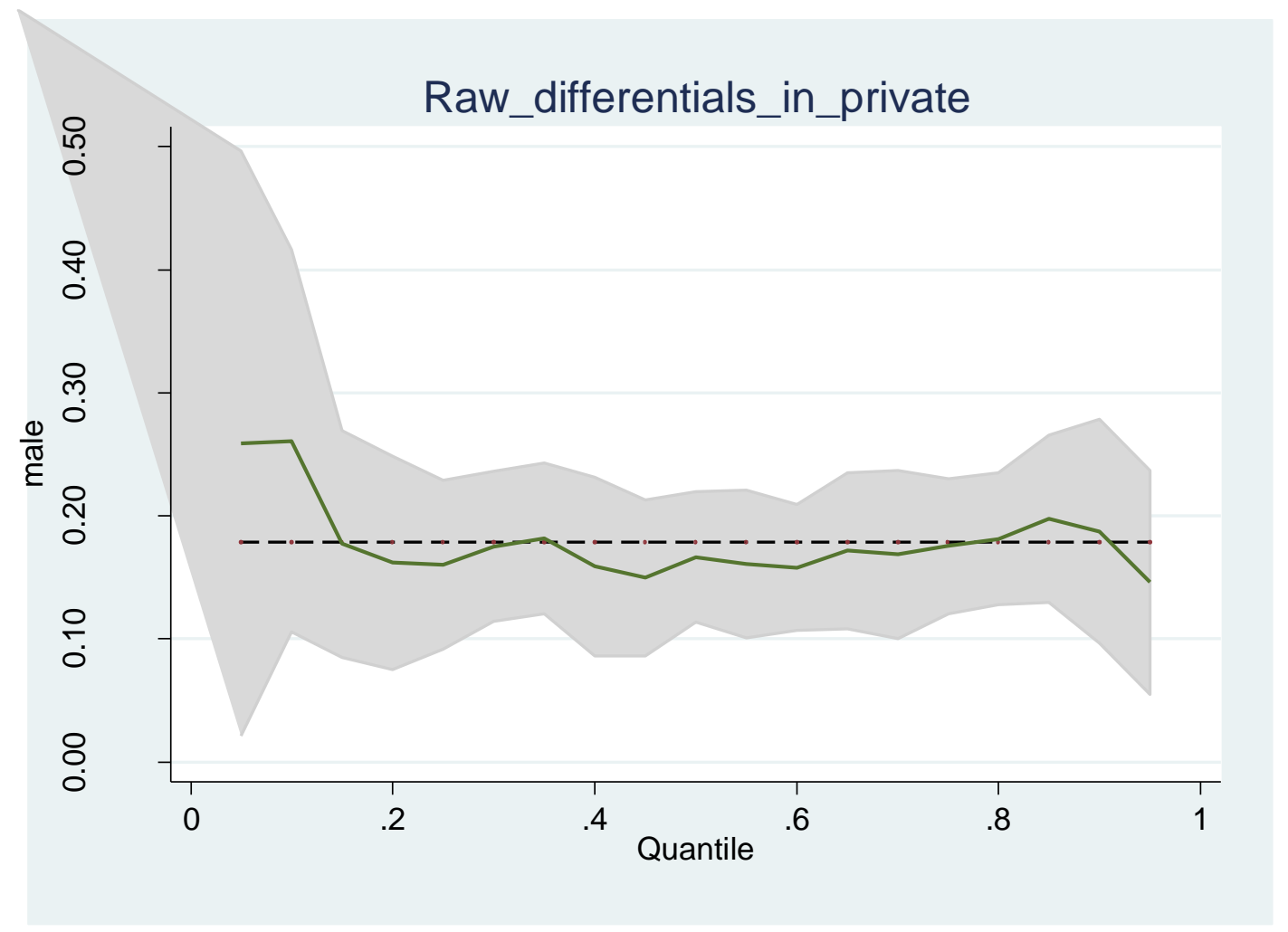

Figure 5. Gender wage gap in private sector by OLS and quantile regression

\section{Conclusion and policy implication}

\subsection{Conclusion}

The previous sections have analyzed in detail the gender wage gap across wage distribution on the entire sample as well as each labor group. Table 9 presents the summary results of the existence of sticky floor and glass ceiling on the labor market in Vietnam. The overall results of the whole sample show that there is sticky floor effect but no glass ceiling in Vietnam labor market. However, the results are different when analyzing in detail on each labor group. In terms of urban and rural areas, the sticky floor exists but the glass ceiling effect does not in both areas.

In terms of state and private sectors, the glass ceiling only exists in the state sector, while the stick floor is only present in the private sector. The cause may be that males are often assigned senior or important position than females. Females are still able to participate in high-level leadership but in fact, such cases are quite rare. If this happens, females often receive lower wages than men for the same position. One other reasonable explanation for this result is the difference in wage policy for two sectors. The private sector is often more competitive and there are no strict wage scales as in the state sector. 


\subsection{Policy implications}

With statistical evidence on the existence of sticky floor glass ceiling effect in the specific groups, this study proposes some policy implications to reduce these two effects and enhance the gender equality. Policies should be designed to increase female labor force attachment, which is expected to reduce 'statistical discrimination' against women. By quantile regression techniques, this study has clarified some specific labor groups which are concerned with the presence of glass ceiling and sticky floor effects. It is necessary to propose appropriate policies for each target group to overcome these effects. The implications suggested by this study can be divided into three categories: some general suggestions to reduce both of effects, some specific suggestions to reduce sticky effects, and some specific suggestions to reduce the glass ceiling effect.

General suggestions to reduce both of effects

Firstly, it is required to formulate a number of gender policies suitable to Vietnam's socioeconomic conditions. Specifically, parental leave policies and day care provisions will enable women to better participate in the labor market. It is necessary to construct a strong support system for working women, such as fully paid maternity leave, access to kindergartens and health-care facilities. One of the reasons that women are confined to the labor market is that women are the ones who have to take care of most of the children in the family. So, Arulampalam et al. (2007) argued that these policies can provide motivation for women to learn to improve their own human capital as well as to have more time to work and improve their productivity.

Secondly, according to Dolado et al. (1996) and Arulampalam et al. (2007), the good minimum wage legislation can help create smaller gender wage gaps and reduce sticky floor effects.

Thirdly, the press and the media also need to provide positive information about a standard perspective on gender equality. According to a report by JobStreet.com, both genders are aware of how men are being privileged over women. In particular, men are said to be more likely to be promoted, receive higher priority in the hiring process, gain higher salaries, and be more likely to be evaluated for better performance.

Sticky floor effect exists in both urban and rural areas. In both areas, a common perception in society is that women must be the ones who take responsibility for most of the housework in family. This hinders the progress in a woman's career as well as her productivity. In addition, when recruiting people, employers often assume that women will not be committed to permanent and effective work as men because of social discrimination. Hence, employers discriminate against women when they enter the labor market because they expect future career interruptions.

For the sticky floor effect

Sticky floor takes place in the private sector but not in the state sector. In the state sector, 
wages for employees, including managers, are defined by clear pay scales. Therefore, the finding of no evidence for the glass ceiling effect in the public sector is reasonable. For the private sector, promotions and wages are often governed by the employers. For profit purposes, employers are willing to pay a very low wage for low-level jobs which are often taken on by females. This might be the cause of the sticky floor effect in the private sector. Therefore, policies to limit the sticky floor effect should focus on the low-wage segment of jobs in private sector.

Chi and Li (2008) found that there is a sticky floor effect that can be explained by a lower female educational attainment. When parents perceive that return to investment on their sons is often greater than that of their daughters, they invest more in education and health care for their sons, especially under low living standard conditions of rural areas. In the long term, this also leads to future wage inequality and sticky floor effect.

Dollar and Gatti (1999) found that economic growth will further reduce the effects of adhesion, and this has been demonstrated in low income. In addition, income inequality which is represented by the Gini coefficient also correlates very strongly with the sticky. Countries that suffer from higher income inequality also experience larger gender wage gap at the bottom of the distribution. Therefore, the policies that promote a country's economic growth also contribute to reducing sticky floor effect indirectly.

Programs and policies to support low-paid women need to focus on the causes of job segregation, in which women often focus on low-wage jobs. Policies also aim at encouraging and motivating females to study and improve their education, enhance their skills, and become more involved in the occupational and industrial segments which men dominate because of prejudice against women.

Furthermore, according to Arulampalam et al. (2007), government should complete more of the minimum wage legislation and collective bargaining institutions. This may play an important role in reducing the gender wage gap at the bottom of the wage distribution and therefore help decrease the sticky floor effect.

For the glass ceiling effect

Dollar and Gatti (1999) also demonstrated that glass ceiling effect may be more likely to occur in richer countries. Therefore, in the process of promoting national economic growth, government should pay attention to potential consequences, named glass ceiling effect which can exacerbate the inequality in society.

Glass ceiling exists only in rural areas. In urban areas, women are more likely to work in a more advanced working environment and have better conditions of promotion than in rural areas. Child care services as well as employment of domestic workers are also more convenient. Therefore, urban women can assume more important positions in the business than in rural areas. Thus, glass ceiling effects do not exist in urban areas but exist in rural areas 


\section{References}

Adamchik, V., Hyclak, T., \& King, A. (2003). The wage structure and wage distribution in Poland, 1994-2001. International Journal of Manpower, 24, 916-946.

Agrawal, T. (2013). Are there glass-ceiling and sticky-floor effects in India? An empirical examination. Oxford Development Studies, 41(3), 322-342

Albrecht, J., Bjorklund, A., \& Vroman, S. (2003). Is there a glass ceiling in Sweden? Journal of Labor Economics, 21(1), 145-177.

Anh, T. T. T. (2015). Analyzing effects of qualifications on wage in Vietnam: A quantile regression (in Vietnamese). Journal of Economic Development, 26(1), 95-116.

Anh, T. T. T. (2015). Effects of qualifications on wage in rural and urban sectors in Vietnam: A quantile regression approach (in Vietnamese). Journal of Economic Studies, Danang University of Economics, 2015(3), 11-20.

Arulampalam, W., Booth, A. L., \& Bryan, M. L. (2007). Is there a glass ceiling over Europe? Exploring the gender pay gap across the wage distribution. Industrial $\mathcal{E}$ Labor Relations Review, 62(2), 163-186.

Booth, A. L., \& Francesconi, M. (2003). Union coverage and non-standard work in Britain. Oxford Economic Papers, 55(3), 383-416.

Buchinsky, M. (1994). Changes in the U.S. wage structure 1963-1987: Application of quantile regression. Econometrica, 62(2), 405-405.

Card, D. (1995). The wage curve: A review. Journal of Economic Literature, 33(2), 785-785.

Chi, W., \& Li, B. (2008). Glass ceiling or sticky floor? Examining the gender earnings differential across the earnings distribution in urban China, 1987-2004. Journal of Comparative Economics, 36(2), 243-263.

Christofides, L. N., Polycarpou, A., \& Vrachimis, K. (2013). Gender wage gaps, 'sticky floors' and 'glass ceilings' in Europe. Labor Economics, 21(C), 86-102.

de la Rica, S., Dolado, J., \& Llorens, V. (2008). Ceilings or floors? Gender wage gaps by education in Spain. Journal of Population Economics, 21(3), 751-776.

Dolado, J., Kramarz, F., Machin, S., Manning, A., Margolis, D., Tuelings, C., Saint-Paul, G., \& Keen, M. (1996). The economic impact of Minimum Wages in Europe. Economic Policy, 11(23), 317-372.

Dollar, D., \& Gatti, R. (1999). Gender inequality, income, and growth: Are good times good for women? World Bank Working Paper, May 1999.

Finseraas, H., Johnsen, A., Kotsadam, A., \& Gaute, T. (2016). Exposure to female colleagues breaks the glass ceiling evidence from a combined vignette and field experiment. European Economic Review. http:/ /dx.doi.org/10.1016/j.euroecorev.2015.11.010 
Hao, L., \& Naiman D. Q. (2007). Quantile regression. Sage Publications, Thousand Oaks.

Hung, P. T., \& Reilly, B. (2009). Ethnic wage inequality in Vietnam. International Journal of Manpower, forthcoming, 30(3), 192-219

Kee, H. J. (2006). Glass ceiling or sticky floor? Exploring the Australian gender pay gap: The economic record. The Economic Society of Australia, 82(259), 408-427.

Koenker, R. (2005). Quantile regression. Cambridge.

Koenker, R., \& Bassett, G. (1978). Regression quantiles. Econometrica, 46(1), 33-50.

Liu, A. Y. C. (2004). Gender wage gap in Vietnam: 1993 to 1998. Journal of Comparative Economics, 32(3), 586-596.

Machado, J., \& Mata, J. (2005). Counterfactual decomposition of changes in wage distributions using quantile regression. Journal Applied Economics, 20, 445-446.

Mincer, A. J. (1974). Introduction to schooling, experience, and earnings. NBER Chapters. In Schooling, experience, and earnings (pp. 1-4). National Bureau of Economic Research, Inc.

Pham, T.-H., \& Reilly, B. (2007). The gender pay gap in Vietnam, 1993-2002: A quantile regression approach. Journal of Asian Economics, 18(5), 775-808. 